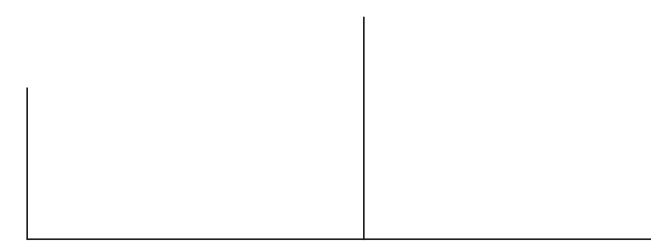

Rev. Latinoam. Psicopat. Fund., III, 1, 62-70

\title{
O tratamento e o diagnóstico em instituição para crianças psicóticas: o caso S.*
}

\author{
M. Cristina M. Kupfer
}

\begin{abstract}
O presente artigo relata o tratamento de S., uma criança que começou a encontrar o caminho de sua subjetivação a partir da aprendizagem da escrita. Partese da hipótese de que a aprendizagem da escrita coloca em jogo uma operação significante que constrói a escrita e, ao mesmo tempo, o sujeito. Essa hipótese de trabalho permite ainda afirmar que há lugar para um trabalho educativo no tratamento da psicose infantil.
\end{abstract}

Palavras-chave: Psicose infantil, escrita, alfabetização, tratamento

\footnotetext{
Apresentado no Congresso Internacional sobre Austimo e Psicoses Infantis, realizado em São Paulo, de 8 a 10 de agosto de 1997.
} 


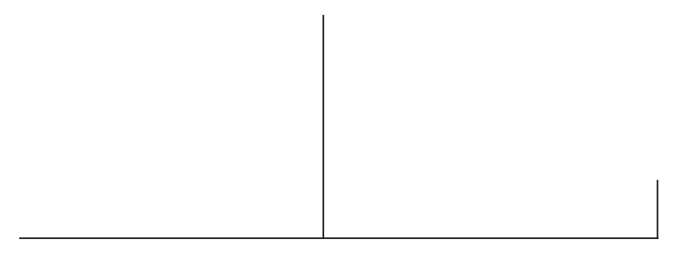

Entre os vários eixos que sustentam o tratamento de crianças psicóticas e autistas que conduzimos no Lugar de Vida, existe um que foi construído ao longo de nossa história. Trata-se do eixo da educação.

Farei, então, uma breve exposição sobre o trabalho educacional que realizamos. Passarei em seguida a uma discussão a propósito do lugar da escrita e da aprendizagem da escrita no tratamento de crianças psicóticas, partindo do caso de uma menina que tratamos.

É a partir deste exercício de leitura das produções desta criança que poderemos extrair uma estrutura, e falar então do diagnóstico tal como podemos formulá-lo na instituição.

Partimos da experiência clínica que as crianças nos ajudam a atravessar, bem como da teoria psicanalítica e da experiência que nos é transmitida pelas publicações Les feuillets du courtil, Préliminaire, Escritos de la infancia, de Buenos Aires, entre outras de inspiração lacaniana.

Desde o início de nossa experiência, os pais nos apresentam uma demanda escolar. Eles querem muito que seus filhos possam seguir uma escolarização, mas as dificuldades são muitas.

Os pais têm, aliás, razão. Seus filhos não são bobos, existem até aqueles que lêem ou mesmo escrevem. Os teóricos também localizam, nas crianças psicóticas, "ilhas de inteligência", ou, ainda, "qualidades intactas". Naquilo que nos concerne, fomos sempre surpreendidos pela emergência repentina dessas qualidades que surgiam, às vezes, durante o tratamento, mas que desapareciam, em muitos casos, tão rapidamente como tinham aparecido.

Também ficamos surpresos pela leitura de um Manual de Psiquiatria da Criança, de Postel e Quetel (1987). Essa leitura nos indicou que o primeiro tratamento proposto a uma criança psicótica foi de natureza educacional. Refere-se ao tratamento proposto por Jean Itard a Victor de l'Aveyron. Efetivamente, Itard quis educar Victor, uma criança que habitava a linguagem da mesma maneira que o fazem hoje as crianças psicóticas. 


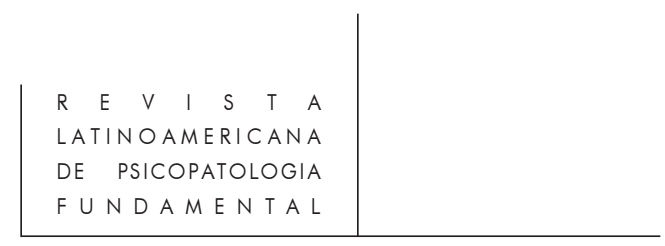

A história da psiquiatria é pontuada desde então por relatórios de médicos que souberam depreender em algumas crianças, consideradas na época como crianças idiotas, o que eles denominavam "as qualidades intactas".

Atualmente, no entanto, é a partir dos movimentos antimanicomiais que foi aberto um lugar na escola para essas crianças.

Em nossa instituição de tratamento escolhemos, a partir dessa reflexão, abrir um espaço nomeado educacional para as crianças psicóticas. Não estamos, aliás, sozinhos nessa empreitada. Maud Mannoni abriu o caminho, e muitas outras experiências a seguiram, de perto ou de longe. Atualmente, no Courtil por exemplo, pode-se acompanhar toda uma discussão a propósito do lugar do discurso do mestre em relação ao discurso do analista, e os intervidores ${ }^{1}$ que ali trabalham nomeiam-se "educadores".

Os efeitos da abertura de um espaço educacional puderam ser vistos desde o início. "Meu filho vai à escola", é o que os pais podem dizer aos seus vizinhos. O significante "escola" cai melhor que o significante "hospital", observa A. Jerusalinsky (1997) no seu texto "A escolarização das crianças psicóticas". E se ele cai bem é porque "cava" um lugar para essa criança no discurso social. Para a criança "é pegar ou largar", empregando-se aqui uma expressão muito comum entre os intervidores do Courtil.

Entretanto, a designação de um lugar no discurso social não é suficiente - é preciso que a criança possa sustentá-lo. No entanto, ela está exposta à sua inabilidade para manobrar esse discurso, por falta de referenciais fálicos.

Precisamos, então, tentar criar outros dispositivos que possam ajudar, que possam ter um valor de suplência para essas crianças. Nossa instituição é, assim, uma instituição de tratamento das psicoses infantis que emprega, entre outros, recursos educacionais como coadjuvantes desse tratamento. Os ateliês são um exemplo, bem como os passeios por espaços exteriores à instituição.

Entre esses recursos, existe um atualmente que merece um pouco mais de atenção, por causa dos efeitos que tem o poder de provocar: trata-se da aprendizagem da escrita.

A origem de nossa atenção a esse eixo está situada no acompanhamento de certos casos de crianças que ganharam uma certa organização libidinal, uma diminuição da agitação motora e mesmo uma entrada na palavra quando a escrita surgiu para elas. De maneira oposta, era surpreendente ver que, em outras crianças, uma escrita absolutamente vazia tinha se instalado, e nada de subjetivante se produzia.

1. Intervenant no original. 


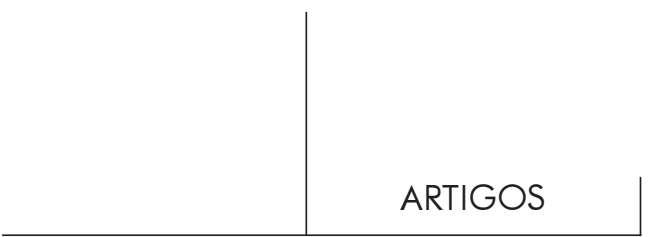

Colocamo-nos, então, a estudar a natureza da escrita e seu modo de aquisição, ou seja, a alfabetização. Entre os escritos que atravessamos, existe um que nos foi particularmente útil: trata-se de uma tese de Doutorado. "O quebra-cabeças: a instância da letra na alfabetização”, de Sonia Borges Vieira da Mota (1992).

\section{A natureza da escrita}

Partiremos primeiramente do fato de que a escrita não pode de maneira alguma ser reduzida a uma simples representação da linguagem falada. Quando se escreve, uma espécie de vida independente toma a frente. Se Lacan nos diz que a linguagem, de uma maneira geral, é um sistema que se reproduz no interior de si mesmo, com uma extraordinária e terrível fecundidade, isto vale seja para a linguagem falada, seja para a linguagem escrita. Quando se escreve, produz-se um outro texto, que não está ali quando se fala. Escrever é produzir um "a mais", que é o fruto dos encontros sintáticos, das vírgulas, da posição das frases, de seu encadeamento. É por isso que se pode afirmar que a aprendizagem da escrita pode produzir efeitos subjetivantes que não são necessariamente os mesmos da linguagem falada. É por isso que pode haver aí um sujeito da escrita antes de se instalar um sujeito da palavra. As crianças autistas, que aprendem a escrever por meio de um computador e não acedem à palavra, o atestam bem.

\section{A presença do Outro}

Mota nos diz que o estudo da alfabetização nas crianças normais é um estudo no qual trata-se de acompanhar "os efeitos da intensificação das relações da escrita da criança com sua própria escrita", ou seja, os efeitos da escrita sobre a escrita. Quando a "boa" alfabetização cria os meios de liberar a criança da exigência da representação, acompanha-se a construção de uma escrita muito singular no início, marcada por palavras que são somente conjunções de letras, mas que dão um grande prazer à criança, pois ela se vê tomada por esse movimento no qual é a escrita que pouco a pouco se impõe, e não pela necessidade de escrever corretamente o que se fala.

Nesse movimento de surgimento da escrita é, entretanto, importante e evidente que aí haja Outro. "Quando se trata da aquisição da linguagem falada, a criança se escuta na palavra da mãe. Quando se trata da aquisição da escrita, a criança lê/ interpreta sua escrita no texto/discurso do Outro. Então, o Outro da criança, com quem ela dialoga na sua escrita, são os discursos e os textos, as histórias de gatos e ratos que circulam na classe, sustentadas transferencialmente pelo professor". 


\section{Significante e letra}

Se afirmamos que na escrita não há correspondência entre palavra e coisa, o que vemos na escrita não tem relação direta com a percepção; a relação se faz com a materialidade do texto. O que é escrito é o traço, e não a percepção. O que vemos é, então, o efeito do trabalho da letra, que se revela pela instalação da operação significante. Retomemos que, segundo Lacan, a letra é a sustentação material que o discurso concreto empresta à linguagem.

Esse traço que se revela na escrita não é mais o traço inscrito primordialmente, mas já é um feixe de relações: é isto que nos ensina Freud no seu texto "O bloco mágico".

\section{A função do recalque}

Sonia Mota nos faz acompanhar a ação do recalque no estabelecimento de uma escrita que deve se curvar ao código. Pedro é uma criança que inclui na sua escrita uma letra singular: um pequeno coração tem, para ele, o mesmo valor que os A e os B. Ele escreve assim, por exemplo: "Pedro tem mamãe e vlpu bom". O que ela nos conta é que Pedro precisou renunciar a seu traço, ou seja, recalcá-lo, fazendo-o curvar-se ao pacto simbólico. Esse recalque ocorrerá pelo efeito da ordem simbólica que se lhe impõe, e não pelo efeito de um ensinamento.

O significante não pode se instalar senão pelo recalque de seu oposto, ou pela queda de tudo o que poderia ter vindo em seu lugar. Quando se trata da escrita, é preciso que haja também recalque do valor próprio à letra e seu nome.

\section{A presença do sujeito}

Estudando as primeiras manifestações da escrita na criança, Mota extraiu daí formas muito singulares de escrita. São exatamente essas particularidades que mostram a possibilidade do surgimento do sujeito na linguagem. Os efeitos de transformações dessa escrita testemunham a presença de um sujeito em trabalho de construção do significante, em trabalho de operação significante. Não, naturalmente, de um sujeito que domina sua escrita, mas um sujeito que é o efeito dela. Pode-se, então, concluir que o que está em jogo no trabalho de aquisição da escrita não é uma objetivação, mas uma subjetivação. Por sua condição de fato de linguagem, o ato de escrever é sustentado por processos simbólicos e imaginários que levam ao advento de um sujeito. 


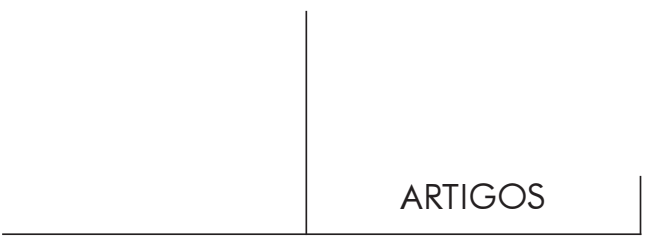

Quando aprendem a escrever, as crianças colocam em jogo a operação significante que constrói uma escrita, mas que as constrói pelo mesmo ato. É um exercício de "letração", que as ordena, as reordena, a partir da interpretação do Outro.

\section{$\mathrm{O}$ caso $\mathrm{S}$}

Quando o tratamento de S começa, verificamos que ela diz algumas palavras - escrever, bola etc. Mas não se dirige ao outro. Sua linguagem é ecolálica. Sua mãe nos conta que ela gosta muito de "escrever". Mas o faz sobre seu corpo e, às vezes, nas paredes.

Ela se interessa por tudo que tem relação com a feminilidade: os cabelos, os vestidos etc. Sabemos também que sua mãe dá muita importância aos cabelos de $\mathrm{S}$; ela os trata com muito cuidado e os penteia cuidadosamente.

$\mathrm{S}$ efetivamente gostava muito de escrever e desenhar sobre seu corpo e nas paredes. Mas havia um traço que ela repetia regularmente. Trata-se de algo que chamaremos "cobrinha"; um traço sinuoso que ela inscrevia na sua testa.

Nessa época, S começou a fazer desenhos no papel: as bolas, umas dentro das outras, sem ordem. Certo dia, uma de nossas intervidoras, uma educadora, "interpretou" seu desenho: ela viu ali uma "menina", supondo que a grande bola fosse o rosto, e, as pequenas, os olhos, a boca e o nariz. Ela fez o que podemos nomear de "antecipação significante". Pouco importa se era esta efetivamente a intenção de S. O que importa é que, a partir do desejo de analista, como observou Eduardo Vidal neste mesmo Congresso, uma interpretação ocorreu. S a aceitou e a adotou. Verificamos, posteriormente, que este nome adquiriu para $S$ um valor significante. $\mathrm{S}$ começa, então, a desenhar a "menina" com mais detalhes, e os nomeia: "O olho, a boca etc.". Mais tarde ela coloca aí um corpinho e braços.

Um dia, ela inscreve, na testa de seu desenho de menina, sua cobrinha. Nesses desenhos vemos também aparecer o desenho dos cabelos.

Nessa época, observamos que S começa a fazer frases curtas, mas encadeadas, começa a se interessar por outros objetos, como o espelho, o telefone e as bonecas. Sua agitação cede. Voltada para as revistas, descobre as mulheres da publicidade, as maquiagens, a lingerie. Podemos dizer que o significante "menina" se desdobra, desloca-se, e assistimos à produção de metonímias parciais?

Ocorre, então, um terceiro fato importante: $\mathrm{S}$ escapa da sala de trabalho e se depara com uma mulher da limpeza que lhe pergunta seu nome. S responde, o que não faz nunca, com um nome completamente inventado; alguma coisa que começa por "Cla", mas que não chega a ser um nome conhecido. Em seguida, ela volta à sala de trabalho, mas passa mal. Dobra-se sobre si mesma e vomita. O encontro com a demanda do Outro lhe é insustentável, e é com o seu corpo que ela responde. 


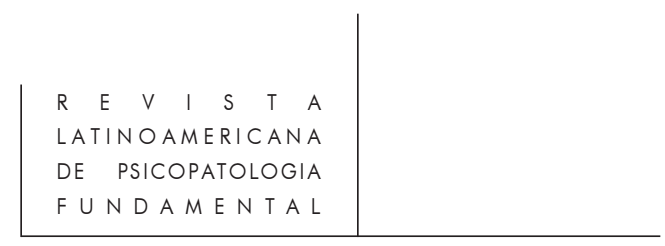

Esse acontecimento é acompanhado por um interventor da instituição que trabalha com $\mathrm{S}$ no ateliê de jogo.

A mãe conta ao intervidor - o que chamamos de "referência" - que as duas meninas ( $\mathrm{S}$ e sua irmã) construíram bandeirinhas. A mãe as deixou penduradas para que o pai as visse, quando chegasse à noite. Esse episódio é marcante para essa família, pois trata-se de uma rara ocasião na qual o pai é incluído. Esse pai chega até a ir à Festa Junina que tivemos na instituição. S repete, então, muitas vezes a produção dessas bandeirinhas durante $o$ ano.

A partir do trabalho educacional, recolhemos ainda um novo fragmento do deslocamento que acompanhamos. O intervidor desenha uma figura humana; na cintura, faz uma curva sinuosa, que se parece muito com a famosa "cobrinha". S pega o lápis e começa a cortar com um pequeno traço horizontal cada morrinho, digamos, da curva. O que resulta num encadeamento de letras A.

Novo deslocamento. No trabalho educacional, fazemos a chamada todos os dias. Temos, aliás, o hábito de dizer, rindo, que nossa chamada se faz com um C maiúsculo: é a chamada do Outro ao Sujeito, para que este venha inscrever seu nome próprio ao lado daquele que escrevemos em letra de forma. Ele é então convidado a assinar seu nome, e cada criança pode fazê-lo como quiser ou puder. E, então, um dia, $\mathrm{S}$ assina seu nome com a cobrinha. $\mathrm{E}$ depois dos A que surgiram na cintura da figura humana, é com eles que agora ela assina seu nome, AAA, enquanto faz a divisão silábica: SA-MI-RA. Agora, ela marca todos os espaços da instituição com esse seu traço, que a representa.

Algum tempo depois, apresentamos às crianças a escrita de algumas palavras. Entre elas, a palavra "mão". Não esqueçamos que tentamos sempre colocar à disposição da criança o maior número de palavras possível, de atividades, de situações para "pegar ou largar". S pega a palavra mão, e escreve ao lado o M e o A, soletrando-as. Seu traço se desdobra.

Os deslocamentos continuam. A Festa Junina se aproxima novamente. Fazendo seu traço característico, ela lê: Fes-ta-Ju-ni-na.

Finalmente, o deslocamento mais recente. S segue atualmente um trabalho individual de aprendizagem da escrita. Fazendo um desenho que representa sua família, ela o assina com seu traço e lê: pai.

Digamos ainda que todos esses movimentos foram recolhidos em nossas reuniões de equipe. Cada intervidor trouxe um, e pudemos acompanhar todos esses deslocamentos construindo um fio entre eles a partir das reuniões nas quais cada intervidor traz o que seu desejo pôde colher do material que S apresenta durante nossas múltiplas atividades.

Voltemos agora à teorização apresentada a propósito da escrita. 


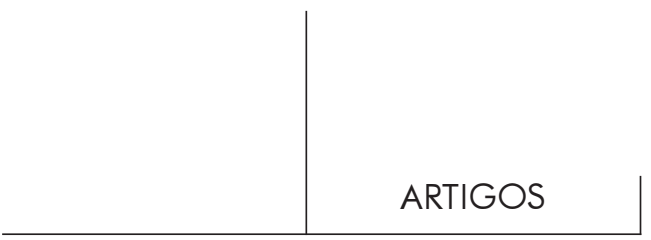

Acompanhamos a partir desse caso a construção de uma marca, inscrita sobre o corpo, que sofreu um deslocamento e que se tornou traço. Qual é sua natureza? Não se trata de percepção, como dizíamos antes, mas de traço, o que é, por sua vez, feixe de relações. É o efeito do trabalho da letra, é o efeito do encontro com o real da letra. Uma rede de relações, dizíamos, cujas origens podemos aproximativamente reconhecer: os cabelos, o encadeamento de A, o nome próprio, as bandeirinhas, o pai. Trata-se de um traço cuja inscrição originária tem a ver com a escrita: "escrever" é o que ela traz como significante próprio no início do tratamento.

Acompanhamos também os efeitos de subjetivação que surgiram paralelamente aos deslocamentos. A marca se desprende do corpo, que se acalma. Os efeitos devastadores do gozo do Outro, de um Outro não-barrado, podem ser interrompidos por meio de um início de inscrição simbólica trazida pela "letração". Podemos dizer, talvez, que o movimento de subjetivação de $\mathrm{S}$ pode ser atribuído ao poder subjetivante da escrita.

Acompanhamos aí, ainda, um trabalho conduzido em instituição, na qual os intervidores se apresentam, cada um por sua vez, como um outro Outro, barrado, pelo viés das manifestações da cultura, sendo a escrita uma das privilegiadas.

Acompanhamos, finalmente, um deslocamento que pode nos ajudar a falar de diagnóstico. Vejamos, por exemplo, os efeitos da ausência de recalque originário. Se, no lugar da Behajung, de uma afirmação negativa, temos somente uma afirmação afirmativa, o S "escrever" tem dificuldade em se deslocar. Verificamos que esses deslocamentos são parciais, lentos. Quando a letra do alfabeto surge, ela desaparece em seguida para reaparecer somente um ano mais tarde. $\mathrm{O}$ recalque do nome da letra não se faz, e ela escolhe um traço que não pertence ao código. Por enquanto, nada de pacto simbólico. S mostra muito bem que está na linguagem, mas quase não entra no discurso. Ela parece estar petrificada por seu significante, para empregar uma expressão de Alexandre Stevens, e é o tratamento que tenta fazê-la se desvencilhar (ao menos, por exemplo, introduzir, no interior de seu traço, o sistema de diferenças, sem o qual a operação significante não se dá. Propusemos a $\mathrm{S}$, dentre outras intervenções, desenhar sua marca com cores diferentes). Acompanhamos, então, na sua aprendizagem da escrita, as provas estruturais da presença da psicose infantil. S não está engajada nessa vertente da linguagem da qual fala Lacan, que a faz ser um sistema que se reproduz no interior de si mesmo com uma extraordinária e terrível fecundidade. A intrusão do gozo do Outro a faz brecar, e toma seu lugar.

É a partir, então, do tratamento, tal como o conduzimos em instituição, que podemos falar em diagnóstico. Um diagnóstico estrutural, extraído do que nos traz a criança à medida que tenta, a partir de sua entrada na escrita, "cavar" seu lugar de sujeito no discurso. 


\section{Referências Bibliográficas}

Jerusalinsky, Alfredo. "A escolarização de crianças psicóticas". Estilos da clínica Revista sobre a infância com problemas. São Paulo, Pré-Escola Terapêutica Lugar

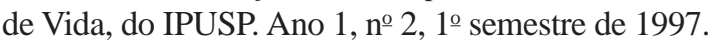

MотA, Sonia B. Vieira (1992). "O quebra-cabeças: a instância da letra na alfabetização". Tese de doutorado apresentada ao Instituto de Estudos da Linguagem da UNICAMP.

Postel, J. e Quetel, C. (org.) (1987). Historia de la psiquiatria. México, Fondo de Cultura Económica.

\section{Resumos}

Este artículo relata el tratamiento de S., una niña que ha empezado a encontrar el camino de su subjetivación a partir del aprendizaje de la escrita. Partimos de la hipótesis de que el aprendizaje de la escrita pone en juego una operación significante que construye la escrita y, al mismo tiempo, el sujeto. Esa hipótesis de trabajo permite aún afirmar la existencia de un lugar para un trabajo educativo en el tratamiento de la psicosis infantil.

70 Palabras llave: Psicosis infantil, escrita, alfabetización, tratamiento

Cet article raconte le traitement de S., un enfant que a commencé a rencontrer le chemin de sa subjectivation à partir de l'apprentissage de l'écriture. On part de l'hypothèse de que l'apprentissage de l'écriture met en jeu une opération significante que construit, à la fois, l'écriture et le sujet. Cette hypothèse de travail permet encore d'affirmer qu'il y a un lieu pour un travail éducatif dans le traitement de la psychose infantile.

Mots clés: Psychose infantile, écriture, alphabétisation, traitement

This article describes the treatment of S., a child who began to find the path to subjectiveness since the handwriting learning time. The author starts from the hypothesis that the handwriting apprentice ship presents a significant operation which both builds up the writing and the subject. This hypothesis allows us to affirm that there is a place for an educational work in the infantile psychosis treatment.

Key words: infantile psychosis, handwriting, instruction in reading and writing, treatment 